\title{
GENDER DIFFERENCES IN SOCIAL MEDIA ADDICTION AMONG ADOLESCENT STUDENTS
}

\section{Gaja Lakshmi. S*}

\section{Dr. Selvaraj. B}

Ph.D.Research scholar, Government Arts College, Coimbatore. ${ }^{*}$ Corresponding Author

Associate Professor, Government Arts College, Coimbatore.

ABSTRACT There is nothing inherently bad with interacting with friends and other members in online or shares the ideas, likes and dislikes. but for a lot of children, the line between the virtual world and offline reality can become quite hazy. The present study made an attempt to evaluate the gender differences and working and non working mother's children on social media addiction. A cross-sectional study was conducted among 136 middle adolescent school students in Coimbatore city. Social media usage was assessed by Social media addiction questionnaire. Demographics variables like gender, siblings, parents working status, family type etc., were collected. To analyze the data t-test was used. The study found out that, a significant difference was observed among male and female school students in social media addiction. Further, there is no significant difference exist between working and non-working mother's children in social media addiction.

KEYWORDS : Social media addiction, gender differences, adolescent students

\section{INTRODUCTION:}

Internet addiction is not yet an officially accepted mental disorder. Researchers have formulated diagnostic criteria for Internet addiction, but it is not included in the Diagnostic and Statistical Manual of Mental Disorders (DSM-5). However, Internet gaming disorder is included as a condition for advance study, and Internet addiction is developing as a specialist area. Internet addiction is described as an impulse control disorder, which does not engage use of an intoxicating drug and is much related to pathological gambling. Some researchers agreed that social media addiction is similar to cell phone and internet addiction disorder. These types of disorders are not new and people have started talking about it since decades ago. Social media addiction can be view as one type of Internet addiction, where individuals exhibit a urge to use social media to excess (Griffiths, 2000). Individuals with social media addiction are often excessively concerned about social media and are driven by an unmanageable urge to log on to and use social media (Andreassen 2014). Social Media has been defined as websites which allow profile creation and visibility of relationships between users (Boyd \& Ellison, 2008); web-based applications which provide functionality for sharing, relationships, group, conversation and profiles (Kietzmann et al., 2011). Statistics show that active social media users the world over are approximate at about two thousand two hundred and six billion, a global diffusion of $30 \%$ which is a rise in number of users by about one hundred and seventy-six Million users in the last year alone. The increase in number of these social media sites, joint with the fast growth and advancement of mobile device technology in the last few years, fixed with the ease of access to broadband and mobile data services have created a major avenue for daily social interaction; encouraging regular profile updates and replies to comments and messages in real time.

Müller \& al.,( 2017) studies examine the gender differences in social network excessive use excessive use is linked to girls while an addictive use is related to boys among excessive users (3.6\% of girls vs. a $4.1 \%$ of boys). While considering past literature results on gender differences are not consistent. In this study by Salehan and Negabahn (2013) didn't discover gender differences among the use of mobile social networking applications and mobile addiction; in reverse to earlier research that suggests that girls are more prone to develop addictive behaviour. According to Henderson, Hinisi and Martin (2006) study concerning the predicting factors that can cause internet addiction among different university student's, explains that factors such as low masculinity, social support and neurotic personality trait act as the predictors for internet addiction. Jalalinejad (2012) states that gender differences also play a important role in Internet addiction. The prevalence of internet addiction in boy's students is higher than girl's students. He also includes that internet addiction also effects social relation. It converts people extra introvert and away from family and society (Cardak, 2009).

\section{Objectives Of The Study}

- To study the gender difference in social media addiction of adolescent school students.

- To study the difference between working and non-working mother's children on social media addiction.

\section{Hypotheses}

1. There will be a significant gender difference in social media addiction among school students.

2. There will be a significant difference between working and non-working mother's children on social media addiction.

\section{MATERIALS AND METHODS}

This study used a cross-sectional study design, and it was conducted at the schools in Coimbatore city. The participants were higher secondary school students. For the purpose of data gathering two questionnaires were used (1). Social media addiction Scale - Student Form: Cengiz Şahin(2018). This is a 5-point Likert type scale which consists of 29 items and 4 sub-dimensions. The questionnaire is a psychometrically valid and reliable instrument, which was designed to be applicable to a broad range of social media addicts. (2) Personal Information Form-It was used to get demographic information of the students like age, class, location of school, name, gender, parents working status etc. In this current study, students were allow to complete the questionnaire with no time limits, the average time required to complete the questionnaire was 15-20 minutes, doubt were cleared then and there, and given a verbal consent that data collected were used for research purpose only. Data entry and analysis were performed using the Statistical Package for Social Sciences (SPSS ${ }^{\circledR}$ ) version 20 . A simple descriptive analysis and 't' test was used to analyze the variables.

\section{RESULTS}

The result shows that, male and female school students differ in social media addiction. The mean value indicate that boys (M78.194) are more addicted to social media than girls students (M65.406) (Tablel). Hence the hypothesis 1"There will be significant gender difference in social media addiction among school student" is accepted. 
Table 1: showing the gender difference in social media addiction of school students

\section{Social media addiction}

\begin{tabular}{lccccc} 
& M & SD & t-value & df & P \\
\hline Male student & 78.194 & 20.102 & 3.855 & 134 & $.000^{*}$ \\
& & & & & \\
Female student & 65.406 & 18.378 & & &
\end{tabular}

Significant at .01 levels

Further, the study result also found out that there is no significant difference between working and non-working mother's children. Hence the hypothesis 2states that, "There will be significant difference between working and nonworking mother's children" is rejected.

Table 2: Difference between working and non-working mother's children Social media addiction

\begin{tabular}{lccccc} 
& M & SD & t- value & df & P \\
\hline Working mother & 75.689 & 19.411 & 1.756 & 134 & $.081^{\mathrm{Ns}}$ \\
Nonworking mother & 69.5641 & 20.634 & & &
\end{tabular}

Ns -Not significant

\section{DISCUSSION}

Social media addiction is a new kind of behavioural addiction among teenagers, which is on the rise because of the deep access of the internet in the Indian masses and all over the world. All the individuals exposed to the internet and networking sites do not develop social media addiction. The factors required for behavioural addiction development are embedded in the personality (Neuroticism, Narcissism, Impulsivity etc) of the individual. For the majority of children, especially those of high school age, time spent on the Internet and engaged in social media is now a part of daily life. There is absolutely no problem and nothing wrong with using social media. The problem comes when someone becomes addicted to social media and overspends their time on those platforms. The level of popularity and use of social media has improved greatly over the years since it was first introduced. Statistics show that active social media users the world over are approximate at about two thousand two hundred and six billion, a global diffusion of $30 \%$ which is a rise in number of users by about one hundred and seventy-six Million users in the last year alone. The magnitude of the use of these different platforms have become a reason for concern in recent times as this phenomenon has driven many researchers across the globe to undertake studies in the area both from the psychology point of view and the angle of communication studies. It has been reported that social media addiction affects about $12 \%$ of users across social networking sites (Wu, Cheung, Ku, \& Hung, 2013).

Many studies on social media usage and mental health have shown that the prolonged use of social media such as Face book is positively associated with mental health problems such as stress, anxiety, and depression and negatively associated with long-term well-being (Malik \& Khan, 2015). Past reviews clearly state that technology addictions have been a giant problem among modern teenagers, even few studies were done on gender differences in internet addiction, this present study especially concentrates on adolescent school student in social media addiction and children of working and non- working mothers. Present study results support the past review like Goel and Garg (2015) Results suggested that male adolescents had higher use of the Internet than female ones.

\section{CONCLUSION}

As a result it may be concluded that there is significant difference between male and female students on social media addiction. But no significant difference was found among working and non working mother's children.

\section{REFERENCES}

1. Andreassen, C. S., \& Pallesen, S. (2014). Social network site addiction: An overview. Current Pharmaceutical Design, 20, 4053- 406l. http://dx.doi .org/10.2174/13816128113199990616

2. Boyd \& Ellison (2008) Boyd \& Ellison (2008) „Social Network Sites: Definition, History \& Scholarship" in Journal of Computer- Mediated Communication 13:210-230.

3. Cardak, (2009). Psychological well-being and internet addiction among university students. Retrieved from https/www.tojet.net/articles/vl2i3/12312.

4. Griffiths, M. D. (2000). Internet addiction: does it really exist? inGackenbach J. (ed). Psychology and the Internet. New York: Academic Press::61-75.

5. Jalaleddin, H., Mohadese, B., Mehdi, H., \& Fatemeh, B. (2013). The Relationship between Emotional Intelligence and Technology Addiction among University Students. International Journal of Collaborative Research on Internal Medi, 5(5), 310-310.

6. Kietzmann, J.H., (2011), "Social media? get serious! Understanding the functional building blocks of social media", Business Horizons, Vol. 54 No. 3 pp. 241-251.

7. Malik, F., \& Khan, N. (2015). Social competence scale for adolescents (SCSA): development and validation within cultural perspective. Journal of Behavioral Sciences, 25(1), 58-77.

8. Salehan, M., \& Negahban, A. (2013). Social networking on smartphones: When mobile phones become addictive. Computers in Human Behavior 29(6), 2632-2639. https://doi.org/10.1016/j.chb.2013.07.003

9. Willi Mueller, Thiago H. Silva, Jussara M. Almeida, and Antonio AF Loureiro. 2017. Gender matters! Analyzing global cultural gender preferences for venues using social sensing. EPJ Data Science 6, 1 (19 May 2017), 5. https: //doi.org/10.1140/epjds/s13688-017-0101-0

10. Wu, A., Cheung, V., Ku, L., Hung, E. (2013). Psychological risk factors of addiction to social networking sites among Chinese smartphone users. Journal of behavioral addictions 2, 160-166. 